\title{
PERSPECTIVAS TRANSVERSAIS: ENTRE COMUNICAÇÃO, ACESSIBILIDADE E INFORMAÇÃO ${ }^{1}$
}

\author{
Maria de Lourdes Alves Figueiredo ${ }^{2}$ \\ Ana Paula da Rosa ${ }^{3}$
}

\begin{abstract}
Resumo
O objetivo deste artigo é entender a educação e a comunicação como importantes ferramentas para a acessibilidade. Utilizamos como base as premissas da Declaração dos Direitos Humanos, que defende a educação como um dos principais instrumentos de manutenção das liberdades e direitos fundamentais, e da Organização das Nações Unidas, que estabelece a igualdade de condições entre as pessoas. O trabalho é estruturado a partir do pensamento de Mario Kaplún, Jesús Martín-Barbero e Ismar Oliveira Soares.
\end{abstract}

Palavras-chave: Comunicação, acessibilidade, inclusão social.

\begin{abstract}
The aim of this article is to understand education and communication as important tools for accessibility. We base our study in the Declaration of Human Rights, which establishes education as one of the main instruments for keeping liberties and fundamental rights, and in the United Nations Organization's legislations, which advocate equality for everyone. We also base this article in some works of Mario Kaplún, Jesús Martín-Barbero and Ismar Oliveira Soares.
\end{abstract}

Keywords: Communication, accessibility, social inclusion.

\section{Acessibilidade e educação: requisito legal ou prática?}

$\mathrm{O}$ respeito à diversidade humana passou a receber atenção diferenciada em meados do século XX. Essa mudança comportamental foi marcada em 10 de dezembro de 1948, quando a Assembleia Geral das Nações Unidas proclamou, pela resolução 217 A (III), a Declaração Universal dos Direitos Humanos. Logo após o preâmbulo deste documento, a Assembleia Geral elenca ensino e educação como instrumentos para a manutenção do respeito aos direitos humanos. Salienta ainda que "cada indivíduo e cada órgão da sociedade deve promover medidas

\footnotetext{
${ }^{1}$ Trabalho apresentado no Intercom Junior no IJ 07 - Comunicação, Espaço e Cidadania do Intercom Sul, Palhoça (SC), em 2014.

${ }^{2}$ Maria de Lourdes é aluna do $4^{\circ}$ período do curso de Comunicação Institucional da Universidade Tecnológica Federal do Paraná (UTFPR) e bolsista no edital TCC Acessibilidade na instituição. Este artigo é parte de uma pesquisa maior, em andamento. E-mail loufigueiredo@yahoo.com.br

3 Ana Paula da Rosa é doutora em Comunicação, orientadora. Professora-adjunta da UTFPR. E-mail anarosa@utfpr.edu.br
} 
que assegurem os direitos e liberdades mencionados na Declaração" (ASSEMBLEIA, 2000).

O ensino é novamente citado na Declaração dos Direitos Humanos no Parágrafo 1 do Artigo XXVI: "Todo ser humano tem direito à instrução" (ASSEMBLEIA, 2000). Em consonância com estes preceitos está a Lei $n^{\circ} 10.861$, que instituiu o Sistema Nacional de Avaliação da Educação Superior - SINAES, e seu Art. $1^{\circ}$ - $\S 1^{\circ}$, que faz referência ao "respeito à diferença e à diversidade" (BRASIL, 2004).

Nesta direção, a legislação brasileira estabelece normas gerais e critérios que promovem a acessibilidade para deficientes que convergem, inclusive, para ações de educação para a cidadania. A Lei $\mathrm{n}^{\mathrm{o}}$ 10.098, de 19 de dezembro de 2000, regulamentada pelo Decreto $\mathrm{n}^{\circ}$ 5.296, de 2 de dezembro de 2004, define no Art. $8^{\circ}$, Inciso I, acessibilidade como "possibilidade e condição de alcance para utilização, com segurança e autonomia, dos espaços, mobiliários e equipamentos urbanos, das edificações, dos transportes e dos sistemas e meios de comunicação, por pessoa portadora de deficiência ou com mobilidade reduzida" (BRASIL, 2000).

A palavra "autonomia", empregada nesta definição, conduz à ideia de liberdade e de independência relacionada à utilização das soluções que eliminam barreiras. A efetivação da não dependência requer a disponibilização de informações adequadas, o que está imbricado com o grau de comunicabilidade das soluções de acessibilidade. Pretende-se assim discutir aqui o papel da comunicação como elemento fundamental e fundante da acessibilidade, levando-se em conta a necessária interação das pessoas com os ambientes.

$\mathrm{Na}$ Lei da Acessibilidade encontra-se no Inciso II do Art. $8^{\circ}$ a definição do termo "barreiras" como sendo "qualquer entrave ou obstáculo que limite ou impeça o acesso, a liberdade de movimento e a circulação com segurança das pessoas" (BRASIL, 2000). Encontrase na sequência deste Inciso, entre outras, a classificação de

barreiras nas comunicações e informações: qualquer entrave ou obstáculo que dificulte ou impossibilite a expressão ou o recebimento de mensagens por intermédio dos dispositivos, meios ou sistemas de comunicação, sejam ou não de massa, bem como aqueles que dificultem ou impossibilitem o acesso à informação (BRASIL, 2000).

O acesso facilitado ao ambiente de ensino através da eliminação de barreiras físicas, sensoriais e atitudinais (SASSAKI, 2011), garante ao indivíduo a participação e a cidadania, promovendo o respeito à diversidade humana e às diferenças.

\section{Deficiência e Mobilidade Reduzida}


Com uma definição ampliada do termo "deficiência", sugerindo inclusive a condição de mobilidade reduzida, a Convenção Interamericana para a Eliminação de Todas as Formas de Discriminação contra as Pessoas Portadoras de Deficiência, Convenção de Guatemala de 28 de maio de 1999, ratificada pelo Brasil através do Decreto n. ${ }^{\circ} 3.956$, de 08 de outubro de 2001 em seu Artigo $1^{\circ}$, item 1, entende que "deficiência significa uma restrição física, mental ou sensorial, de natureza permanente ou transitória, que limita a capacidade de exercer uma ou mais atividades essenciais da vida diária, causada ou agravada pelo ambiente econômico e social” (BRASIL, 2001).

Da mesma forma, para a Associação Brasileira de Normas Técnicas, na Norma Brasileira que trata da Acessibilidade à edificações, mobiliário, espaços e equipamentos urbanos, a definição de deficiência considera de certo modo a condição de mobilidade reduzida em sua definição de deficiência. Conforme o item 3.14 desta norma deficiência, é a "redução, limitação ou inexistência das condições de percepção das características do ambiente ou de mobilidade e de utilização de edificações, espaço, mobiliário, equipamento urbano e elementos, em caráter temporário ou permanente" (ASSOCIAÇÃO, 2004, p.3).

A dificuldade de locomoção ou mobilidade reduzida faz parte do dia a dia de uma considerável parcela da população sem ser percebida e considerada. A fragilidade com sua noção de vulnerabilidade é, pelo senso comum, atribuída às pessoas em determinadas situações, por exemplo, gestantes, lactantes, idosos, obesos, etc. Do ano de 1970 em diante se ampliam as discussões em congressos e conferências sobre pessoas com deficiência, o foco puramente clínico, desde então, compartilha aos poucos espaço com a visão de homem social e seus direitos.

Começam a surgir também as primeiras pesquisas e a sociedade se mobiliza em associações lutando pelos direitos das pessoas com necessidades especiais que fazem parte, conforme a Organização das Nações Unidas - ONU, do maior grupo de minoria do mundo, representando hoje $10 \%$ da população mundial, ou seja, 700 milhões de pessoas deficientes. Ainda segundo a ONU através do Programa das Nações Unidas Para o Desenvolvimento (PNUD), 80\% dos deficientes vivem em países em desenvolvimento (UNITED, 2013). No Brasil, conforme o Instituto Brasileiro de Geografia e Estatística - IBGE no último censo, em 2010, o percentual de deficientes sobe para aproximadamente $23,91 \%$ da população, que possui pelo menos um tipo de deficiência em maior ou menor grau (INSTITUTO, 2010). 
Para além do aspecto altruísta e de políticas assistencialistas praticadas pela sociedade até as últimas décadas do século XX, a Assembleia Geral da ONU institui em 1976, através da Resolução 31/123, a "participação plena e igualdade" como direito das pessoas com deficiência e lança como lema quando proclama o ano de 1981 como Ano Internacional das Pessoas Deficientes (AIPD). A intenção da ONU foi, entre outras, buscar garantias de acessibilidade e igualdade de condições com participação plena e o fim da discriminação e do preconceito (ASSEMBLEIA, 1982).

No que se refere à igualdade e participação plena, lema do AIPD, torna-se necessário o acesso universalizado por meio de mecanismos de fácil compreensão para que a interação com o entorno seja um facilitador para a não exclusão social. Neste sentido, o Programa de Ação Mundial para as pessoas com Deficiência, aprovado pela Assembleia Geral das Nações Unidas, Resolução 37/52, de 3 de dezembro de 1982, lembra que

\begin{abstract}
Para se alcançar os objetivos de "igualdade" e "participação plena", não bastam medidas de reabilitação voltadas para o indivíduo portador de deficiência. A experiência tem demonstrado que, em grande medida, é o meio que determina o efeito de uma deficiência ou de uma incapacidade sobre a vida cotidiana da pessoa (ASSEMBLEIA, 1982).
\end{abstract}

\title{
Inclusão social, acessibilidade e o direito de igualdade
}

A partir da Revolução Francesa, com a Declaração dos Direitos do Homem e do Cidadão (1789), de maneira tímida o princípio da igualdade ganhou visibilidade em quase todo o mundo e, da mesma forma, os esforços em combater atitudes contrárias aos princípios básicos que garantem a dignidade humana. Nesta Declaração as diretrizes primeiras para a inclusão social estão nos artigos $1^{\circ}$ e $4^{\circ}$ :

\footnotetext{
Artigo $1^{\circ}$ - Os homens nascem e são livres e iguais em direitos. As distinções sociais só podem fundamentar-se na utilidade comum;

Artigo $4^{\circ}$ - A liberdade consiste em poder fazer tudo que não prejudique o próximo. Assim, o exercício dos direitos naturais de cada homem não tem por limites senão aqueles que asseguram aos outros membros da sociedade o gozo dos mesmos direitos. Estes limites apenas podem ser determinados pela lei (UNIVERSIDADE).
}

Rumo à igualdade e ao direito à diferença que promovem a inclusão social, a Declaração Universal dos Direitos Humanos (ASSEMBLEIA, 2000) estabelece a proteção universal dos diretos humanos, ponto determinante no reconhecimento da garantia dos direitos de toda pessoa humana. Um dos meios para garantir essa proteção é a educação e o acesso a ela, por parte das 
pessoas com necessidades especiais e mobilidade reduzida, tem relação estreita com as condições de acessibilidade encontradas nas instituições de ensino. Porém, além da eliminação de barreiras físicas e sensoriais, o respeito às diferenças implica promover atitudes que resgatem o deficiente da condição de invisibilidade na sociedade. Não considerar uma característica específica e natural do deficiente faz com que ele se torne invisível na universalidade, excluído socialmente.

Por outro lado Mario Kaplún, comunicador argentino, lembra de outros agentes sociais ao colocarem que a educação não está limitada à formalidade dos sistemas didáticos quando diz que em acréscimo a educação formal e a não formal existe outra modalidade, a educação informal, que é formada por todos os estímulos sociais (KAPLÚN, 2001, p. 74). Neste sentido a responsabilidade da sociedade ocorre através de um processo mais justo colocando a educação como conexão entre a comunicação e a inclusão social.

Similarmente, para Romeu Kazumi Sassaki (1997), consultor em inclusão e reabilitação, de educação profissional inclusiva para a Secretaria de Educação do Paraná dentre outros órgãos públicos e não governamentais e empresas, a inclusão social é responsabilidade de todos os membros da sociedade e pode ser conceituada como

[...] o processo pelo qual a sociedade se adapta para poder incluir, em seus sistemas sociais gerais, pessoas com necessidades especiais e, simultaneamente estas se preparam para assumir seus papéis na sociedade. A inclusão social constitui, então, um processo bilateral no qual as pessoas, ainda excluídas e a sociedade buscam, em parceria, equacionar problemas, decidir sobre soluções e efetivar a equiparação de oportunidades para todos (SASSAKI, 1997, p. 41).

No que se refere à definição para acessibilidade, a NBR 9050 coloca o termo como a "possibilidade e condição de alcance, percepção e entendimento para a utilização com segurança e autonomia de edificações, espaço, mobiliário, equipamento urbano e elementos" (ASSOCIAÇÃO, 2004, p. 2). Possibilidade e condição de alcance implicam, antes de tudo, respeitar a diversidade humana e esta se traduz na heterogeneidade, na multiplicidade de características que tornam as pessoas únicas, sendo necessária a equivalência de oportunidades para que haja igualdade em usufruir dos direitos. Por outro lado é necessário que exista um bom nível de comunicabilidade nas soluções de acessibilidade para que a informação ao usuário possibilite a percepção e o entendimento garantindo, efetivamente, o acesso de modo universal.

Em 2004, o Art. 8o do Decreto ${ }^{\circ} 5.296$, que estabelece normas gerais e critérios básicos para a promoção da acessibilidade, coloca em outras palavras as ideias gerais da NBR 9050 
dirigindo o olhar para as interações sociais para além do aspecto físico dos ambientes e acrescendo a utilização "dos dispositivos, sistemas e meios de comunicação e informação, por pessoa portadora de deficiência ou com mobilidade e reduzida" (BRASIL, 2004).

Tipificando, Romeu Sassaki classifica e define entre os contextos a acessibilidade comunicacional: sem barreiras na comunicação interpessoal, a instrumental: sem barreiras nos instrumentos e a acessibilidade atitudinal: sem preconceitos, estigmas, estereótipos e discriminações, nas pessoas em geral (SASSAKI, 2011).

É interessante considerar a questão da transversalidade entre comunicação, acessibilidade e informação evidenciando a universalização das soluções, o que evita exclusivismos. $\mathrm{O}$ desenvolvimento de projetos de uso exclusivo para pessoas deficientes e a obrigatoriedade na utilização de soluções de acessibilidade por deficientes caracteriza discriminação e segregação. A este respeito a legislação brasileira orienta-se pelas resoluções internacionais como a Declaração Universal dos Direitos Humanos, entre outros, quando postula nos princípios fundamentais da Constituição da República Federativa do Brasil promulgada em 1988 a determinação de que todos são iguais e institui crime a discriminação (BRASIL, 1988).

A mobilização da sociedade, no sentido de garantir o exercício de cidadania e de combater a exclusão de pessoas com deficiência e mobilidade reduzida, passa pelo respeito às diferenças e a promoção de mecanismos que possibilitem a igualdade plena de direitos. Entende-se aqui por igualdade plena aquela que propõe condições para o exercício da mesma, soluções de acessibilidade e comunicabilidade que asseguram a liberdade individual inclusive em optar ou não pelos meios facilitadores.

\section{Legislação e a universalidade nos espaços educacionais}

É considerável o repositório legislativo que assegura a acessibilidade, inclusão social e não discriminação em seus diversos aspectos e em vários níveis para as pessoas com deficiência e mobilidade reduzida.

Temos como base legal a Constituição Federal, que assegura através do Art. 205 o direito de todos à educação, tendo no Art. 206, item I, como princípio do ensino a igualdade de condições para o acesso e a permanência na escola e garantindo pelo Art. 208, item V, acesso aos níveis mais elevados do ensino, da pesquisa e da criação artística, segundo a capacidade de cada um (BRASIL, 1988). 
A Constituição atribui às instâncias governamentais a assistência pública, a garantia (Art. 23, item II) e a promoção da inclusão social das pessoas com deficiência (Art. 203, item IV). Também é dever do Estado, segundo o caput do Art. 227, "garantir o direito à educação e à cultura promovendo acessibilidade, à liberdade de escolhas, à dignidade com maior autonomia e independência, e à convivência comunitária sem discriminação ou negligências" (BRASIL, 1988).

Sobre o aspecto arquitetônico, a Constituição de 1988 estabelece legislação específica sobre a construção de prédios públicos no Art. 227, Parágrafo 20: "A lei disporá sobre normas de construção dos logradouros e dos edifícios de uso público e de fabricação de veículos de transporte coletivo, a fim de garantir acesso adequado às pessoas portadoras de deficiência" (BRASIL, 1988). Em 1994, foram definidas estas normas através da NBR 9050, atualizada em 2004. É importante ressaltar que, nos itens 1.2 e 1.3, para a elaboração desta Norma foram

\begin{abstract}
consideradas diversas condições de mobilidade e de percepção do ambiente, com ou sem a ajuda de aparelhos específicos, como: próteses, aparelhos de apoio, cadeiras de rodas, bengalas de rastreamento, sistemas assistivos de audição ou qualquer outro que venha a complementar necessidades individuais [...] visa a proporcionar à maior quantidade possível de pessoas, independentemente de idade, estatura ou limitação de mobilidade ou percepção, a utilização de maneira autônoma e segura do ambiente, edificações, mobiliário, equipamentos urbanos e elementos (ASSOCIAÇÃO, 2004, p. $1)$.
\end{abstract}

Ao verificar o emprego do termo "percepção" na NBR 9050, observa-se a necessária utilização das impressões sensoriais para se estabelecer interação, comunicação com o ambiente. As condições de compreensão espacial, através de um sentido humano, são de grande importância para as relações humanas, sendo determinante a correta utilização de elementos comunicacionais para transmissão de informações relevantes ao deficiente.

Na Lei $n^{\circ} 7.853 / 1989$, regulamentada pelo Decreto $n^{\text {o } 3.298 / 99}$ que dispõe sobre a Política Nacional para a Integração da Pessoa Portadora de Deficiência, consolida as normas de proteção e dá outras providências, o Art. $7^{\circ}$ coloca como objetivo I do Plano "o acesso, o ingresso e a permanência da pessoa portadora de deficiência em todos os serviços oferecidos à comunidade" (BRASIL, 1999) entre eles a educação e a edificação pública. "Seguindo planos e programas, com prazos e objetivos determinados, aprovados pelo Conselho Nacional dos Direitos da Pessoa Portadora de Deficiência - CONADE" (BRASIL, 1999). E o Parágrafo $5^{\circ}$ do Art. 24 cita especificamente a necessidade de proporcionar acesso igualitário à educação e eliminação das barreiras. No item III do Art. 29 a Política do CONADE refere-se às outras 
acessibilidades, ou seja, "adequação dos recursos físicos: eliminação de barreiras arquitetônicas, ambientais e de comunicação" (BRASIL, 1999).

Em 2009, o Decreto n 7.037 que aprova o Programa Nacional de Direitos Humanos PNDH-3, considerando as dificuldades no cumprimento da Declaração Universal dos Direitos Humanos pelos Signatários, identificou no Eixo III - Universalizar, direitos em um contexto de desigualdades, "a necessidade de reconhecer as diversidades e diferenças para concretização do princípio da igualdade" propõe medidas e programas objetivando a não discriminação (BRASIL, 2009). Conforme Parágrafo $4^{\circ}$ do Art. $4^{\circ}$ que institui o Comitê de Acompanhamento e Monitoramento do PNDH-3, além dos responsáveis indicados para as ações específicas do programa são convidados para execução de suas atividades os "demais Poderes, da sociedade civil e dos entes federados para participarem de suas reuniões e atividades" (BRASIL, 2009), entendendo então a responsabilidade sobre a promoção da inclusão social inclusive no ambiente acadêmico das universidades federais. Destacam-se entre as medidas e ações do PNDH-3 as diretrizes $n^{\circ} 10$ e $n^{\circ} 22$ que dizem respeito a acessibilidade de pessoas deficientes e com mobilidade reduzida como segue:

\footnotetext{
$\rightarrow$ Diretriz 10: Garantia da igualdade na diversidade, Objetivo Estratégico I: Afirmação da diversidade para construção de uma sociedade igualitária, Ação Programática: (a) Realizar campanhas e ações educativas para desconstrução de estereótipos relacionados com diferenças étnico-raciais, etárias, de identidade e orientação sexual, de pessoas com deficiência, ou segmentos profissionais socialmente discriminados. Objetivo estratégico IV: Promoção e proteção dos direitos das pessoas com deficiência e garantia da acessibilidade igualitária, Ações programáticas: "a": Garantir às pessoas com deficiência igual e efetiva proteção legal contra a discriminação; (b) Garantir salvaguardas apropriadas e efetivas para prevenir abusos a pessoas com deficiência e pessoas idosas; (c) Assegurar o cumprimento do Decreto de Acessibilidade (Decreto $\mathrm{n}^{0}$ 5.296/2004), que garante a acessibilidade pela adequação das vias e passeios públicos, semáforos, mobiliários, habitações, espaços de lazer, transportes, prédios públicos, inclusive instituições de ensino, e outros itens de uso individual e coletivo; (d) Garantir recursos didáticos e pedagógicos para atender às necessidades educativas especiais; (e) Disseminar a utilização dos sistemas braile, tadoma, escrita de sinais e libras tátil para inclusão das pessoas com deficiência em todo o sistema de ensino.

$\rightarrow \quad$ Diretriz 22: Garantia do direito à comunicação democrática e ao acesso à informação para consolidação de uma cultura em Direitos Humanos, Objetivo Estratégico I: Promover o respeito aos Direitos Humanos nos meios de comunicação e o cumprimento de seu papel na promoção da cultura em Direitos Humanos, Ações Programáticas: [...] (g): Promover a eliminação das barreiras que impedem o acesso de pessoas com deficiência sensorial à programação em todos os meios de comunicação e informação, em conformidade com o Decreto $\mathrm{n}^{\circ} 5.296 / 2004$, bem como acesso a novos sistemas e tecnologias, incluindo Internet. (BRASIL, 2009).
}

\section{Educomunicação : a partilha dos acessos}


Os processos comunicacionais nas interações sociais estão para a sociabilidade como a comunicação está para a educação. A socialização dos indivíduos perpassa os grupos, através da troca de conhecimentos entre seus membros desenvolvendo-se as bases dos sistemas constitutivos da sociedade. O intercâmbio de novos saberes sugere maior "visibilidade do indivíduo e nesta construção de visibilidade a ideia importante então é o 'entorno', o novo ecossistema" (MARTÍN-BARBERO, 2009).

Da ideia do entorno, a partir da nossa visão e da visão do outro como ecossistema, Jesús Martín-Barbero, teórico espanhol da comunicação da América Latina, ao se referir a intervenção dos meios na comunicação, traz o termo "ecossistema" para o ambiente educacional como "ecossistema comunicativo" (MARTÍN-BARBERO, 2000, p. 54). Entendese que os sistemas de comunicação são sistemas de educação e formação simbólica, portanto, são pertencentes à esfera do educacional. Logo, quando se fala em dar visibilidade ao indivíduo é preciso que os processos comunicacionais contemplem todos os indivíduos da mesma maneira, dando-lhes oportunidade de acesso aos meios, sobre os meios e de diálogo com eles.

Na mesma direção, essa construção do sentido participativo através de ações educativas que promovam equilíbrio de valores e igualdade de condições, Mário Kaplún lembra os diálogos educativos a partir das expectativas dos educandos:

Lo que podría a la escuela es el concebir la educación como un conjunto articulado de estrategias de comunicación. La comprensión de que el educando -niño o adultoque acude a ella no es solo un receptor sobre el cual verter conocimientos, sino un emisor en potencia (KAPLÚN, 2001, p. 186).

Kaplún, estendendo sua visão sobre o espaço educacional a fim estabelecer um ambiente democrático onde os processos de aquisição de conhecimento tornem-se parte dos ecossistemas comunicativos, coloca que

Una escuela que se proponga ser integradora, construtora de la interculturalidad, necesita no solo respetar esos códigos cognitivos y abstenerse de avasallarlos, sino incorporalos positivamente y partir de ellos (KAPLÚN, 2001, p.187).

Visando um ambiente de suporte aos ecossistemas comunicativos com saberes fragmentados (MARTÍN-BARBERO, 2000, p. 55) Ismar de Oliveira Soares, Coordenador do Núcleo de Comunicação e Educação da ECA/USP, define Educomunicação como

[...] o conjunto das ações inerentes ao planejamento, implementação e avaliação de processos, programas e produtos destinados a criar e a fortalecer ecossistemas comunicativos em espaços educativos presenciais ou virtuais (tais como escolas, 
centros culturais, emissoras de TV e rádio educativos, centros produtores de materiais educativos analógicos e digitais, centros coordenadores de educação a distância ou "e-learning", e outros....), assim como a melhorar o coeficiente comunicativo das ações educativas, incluindo as relacionadas ao uso dos recursos da informação no processo de aprendizagem. (SOARES, 2000).

Segundo Ismar de Oliveira Soares, um dos procedimentos da Educomunicação requer que a comunicação seja livre e irrestrita, já que "busca rever os conceitos tradicionais de comunicação, como se existisse apenas para persuadir ou fazer a boa imagem dos que detêm poder e fama" (SOARES, p. 2).

A Educomunicação posiciona-se como uma plataforma satisfatória para a efetividade da interação dos elementos envolvidos no processo de inclusão social, em especial em um de seus campos, a educação para a comunicação no qual os educadores são geradores de conscientização. Porém mais do que isso, é imprescindível que este estar ciente perpasse de maneira verticalizada o ambiente educacional permeando o ecossistema comunicativo e valorizando as diferenças. Para além da questão de rampas e sinalização tátil deve existir a disposição de universalizar os espaços eliminando a discriminação. Quando o repertório de conhecimento compilado em livros, periódicos e mídias têm seu acesso limitado a escadas e elevador restrito a servidores, a função social de uma universidade deve ser repensada.

A aplicação da legislação para satisfazer preceitos legais determina a inclusão, mas gera exclusão. Utilizando um símbolo de vagas para deficientes identifica-se um segmento, um grupo específico e nem todos os considerados com dificuldades de mobilidade estão contemplados por este emblema, mas são negligenciados pelos sistemas de comunicação que responde a um requisito legal não a prática. Ao mesmo tempo a noção de acesso e inclusão está muito focada no portador de deficiência e não na sua visão de necessidades especiais, o que amplia muito a visão. Há uma diferença abismal entre o que se imagina que o outro precisa e suas reais necessidades. Este detalhe nem sempre é considerado no trato da diversidade humana.

Além disso, até que ponto o comunicador (jornalismo, RP, publicitário) é preparado para a cidadania e produção de conteúdos relativos à articulação da educação e da comunicação? Ele está transitando em ambientes que viabilizam e promovam este diálogo? As questões de acessibilidade tratadas na legislação, contextualizadas em artigos e projetos são letras mortas em um ambiente excludente. Ao desempenhar seu papel indutivo na construção de uma sociedade justa a academia deve estimular a prática da cidadania participativa. Os bancos universitários não dão conta da problemática, pois ainda que exista a Lei, isto não significa que nas universidades os sistemas que possibilitam a igualdade de condições de 
acesso, além do âmbito arquitetônico, estejam instalados. É pertinente que se observe ainda, sob quais pontos de vista tais dispositivos são comunicados, como são percebidos e se estão disponíveis a todos. Mais do que o comprometimento com a produção de conhecimento esperase que existam nos ambientes educacionais elementos que estimulem a aplicação desses saberes acadêmicos na construção de uma sociedade inclusiva.

\section{Considerações finais}

Não considerar as diferenças ou uma característica específica e natural do deficiente faz com que ele se torne invisível na universalidade. É importante considerar que os meios facilitadores para a uma participação plena quando desprovidos de comunicabilidade determinam também a invisibilidade das soluções de acessibilidade. E quando estas não são percebidas contribuem para o distanciamento e a ausência do sentimento de pertencimento, traduzindo-se na exclusão social.

A acessibilidade espacial no ambiente acadêmico mantém relação entre comunicação, educação e informação na medida em que os espaços de conhecimento são democratizados. Considerando que a transferência de conhecimento é comunicação e que a educação é formal, não formal e informal a transversalidade entre educação e comunicação a informação ocupa espaços e efetiva a Educomunicação como inclusão social, em especial nos ambientes de disseminação de conhecimento.

Os processos comunicacionais devem traduzir amplamente e de maneira clara as soluções de acessibilidade e inclusão para todas as parcelas da sociedade. A informação dos recursos disponibilizados aos portadores de necessidades especiais deve apresentar-se através de mecanismos de fácil compreensão, autossuficientes, garantindo um menor grau de dependência com maior autonomia individual. Somente quando este conjunto de condições sobre os mecanismos de informação for garantido é que os processos de inclusão serão desenvolvidos de maneira eficiente e igualitária.

(Artigo recebido em 05/05/2014, aprovado em 07/06/2014)

\section{Referências}

ASSEMBLEIA GERAL DAS NAÇÕES UNIDAS. Programa de Ação Mundial para as pessoas com Deficiência. Documento das Nações Unidas Documento A/37/51. Centro de Documentação e Informação do Portador de Deficiência CEDIPOD de 16/03/1982. 
Legislação internacional, Portal Todos Nós, UNICAMP. Disponível em:

$<$ http://styx.nied.unicamp.br/todosnos/documentos-internacionais/doc-programa-de-acaomundial-para-as-pessoas-com-deficiencia-1982/view>. Acesso em: 23 fev. 2014.

ASSEMBLEIA GERAL DAS NAÇÕES UNIDAS. Declaração Universal dos Direitos Humanos. UNICC, Brasil, Rio de Janeiro, 2000. Acessado em 08 de setembro de 2013. Disponível em: 〈http://unicrio.org.br/img/DeclU_D_HumanosVersoInternet.pdf> .

ASSOCIAÇÃO BRASILEIRA DE NORMAS TÉCNICAS. NBR 9050. Acessibilidade a edificações, mobiliário, espaços e equipamentos urbanos. $2^{\text {a }}$ Edição. Rio de Janeiro, 30 JUN. 2004. Portal da Secretaria Nacional de Promoção dos Direitos da Pessoa com Deficiência. Disponível em:

<http://www.pessoacomdeficiencia.gov.br/app/sites/default/files/arquivos/\%5Bfield_generico _imagens-filefield-description\%5D_24.pdf>. Acesso em: 21 fev. 2014.

BRASIL. Constituição da República Federativa do Brasil de 1988. Disponível em: $<$ http://www.planalto.gov.br/ccivil_03/constituicao/constituicao.htm>. Acesso em: 20 fev. 2014.

BRASIL. Decreto $n^{\circ} 3.298$, de 20 de dezembro de 1999. Regulamenta a lei no 7.853, de 24 de outubro de 1989 (Lei da Corde), dispõe sobre a política nacional para a integração da pessoa portadora de deficiência, consolida as normas de proteção, e dá outras providências. Disponível em: 〈http://www.planalto.gov.br/ccivil_03/decreto/d3298.htm>. Acessado em: 18 fev. 2014.

BRASIL. Lei $\mathrm{n}^{\circ} 10.861$, de 14 de abril de 2004. Sistema nacional de avaliação da educação superior - SINAES. Disponível em: <http://www.planalto.gov.br/ccivil_03/_ato20042006/2004/lei/l10.861.htm>. Acesso em: 21 fev. 2014.

BRASIL. Decreto $n^{\circ} 5.296$, de 2 de dezembro de 2004. Regulamenta as leis $\mathbf{n}^{\circ} \mathbf{1 0 . 0 4 8}$, de 8 de novembro de 2000 e n⿳10.098, de 19 de dezembro de 2000. Disponível em:

$<$ http://www.planalto.gov.br/ccivil_03/_ato2004-2006/2004/decreto/d5296.htm>. Acesso em: 18 FEV. 2014

BRASIL. Ministério da Educação. Decreto n 3.956, de 08 de outubro de 2001 - Convenção Interamericana para a Eliminação de Todas as Formas de Discriminação contra as Pessoas Portadoras de Deficiência - Convenção da Guatemala, 1999. Portal do MEC, Secretaria de Educação Especial, Legislação Específica. Disponível em: <http://www.planalto.gov.br/ccivil_03/decreto/2001/d3956.htm>. Acessado em: 23 fev. 2014. BRASIL. Decreto $\mathrm{n}^{\circ} 7.037$, de 21 de dezembro de 2009. Programa nacional de direitos humanos - PNDH-3 e dá outras providências. Disponível em: <http://www.planalto.gov.br/ccivil_03/_Ato2007-2010/2009/Decreto/D7037.htm\#art7>. Acesso em: 22 fev. 2014.

INSTITUTO BRASILEIRO DE GEOGRAFIA E ESTATÍSTICA - IBGE. Censo demográfico 2010: Características gerais da população, religião e de pessoas com deficiência. Rio de Janeiro: IBGE, p. 1-215, 2010. Disponível em: $<$ ftp.ibge.gov.br/Censos/Censo_Demografico_2010/Caracteristicas_Gerais_Religiao_Deficie ncia/caracteristicas_religiao_deficiencia.pdf $>$. Acessado em: 27 fev. 2014.

KAPLÚN, Mario. A la educación por la comunicaión. La práctica de la comunicación educativa. Segunda Edición, revisada. Quito: CIESPAL, 2001. 262. (Colección Intiyán, Vol. 41). Repositório digital Centro Internacional de Estudios Superiores de Comunicación para 
América Latina (CIESPAL). Disponível em:

<http://186.5.95.155:8080/handle/123456789/96>. Acessado em: 25 fev. 2014.

MARTÍN-BARBERO, Jesús. Desafios culturais da comunicação à educação. Comunicação \& Educação, São Paulo, [181]: 51 a 61, maio/ago. 2000. Portal Univerciencia. Disponível em: $<$ http://revistas.univerciencia.org/index.php/comeduc/article/viewFile/4108/3860>. Acessado em: 24 fev. 2014.

MARTÍN-BARBERO, Jesús. Jesús Martín-Barbero: As formas mestiças da mídia. Entrevista à Mariluce Moura, Edição 163, Portal Revista Pesquisa FAPESP, 2009. Disponível em: $<$ http://revistapesquisa.fapesp.br/2009/09/01/as-formas-mesticas-da-midia/> . Acessado em: 24 fev. 2014.

SASSAKI, Romeu Kazumi. Inclusão, construindo uma sociedade para todos. $2^{\mathrm{a}}$ Ed. Rio de Janeiro: WVA, 1997.

SASSAKI, Romeu Kazumi. Conceito de acessibilidade. Notícia. Portal Escola da Gente, 2011. Disponível em: 〈http://www.escoladegente.org.br/noticiaDestaque.php?id=459> . Acesso em: 23 FEV. 2014.

SOARES, Ismar Oliveira. Educomunicação: as perspectivas do reconhecimento de um novo campo de intervenção social. O caso dos Estados Unidos. Eccos Revista Científica, vol. 2, núm. 2, dezembro, 2000. Disponível em: 〈http://www.redalyc.org/articulo.oa?id=71520205>. Acesso em: 24 fev. 2014.

SOARES, Ismar Oliveira. Mas, afinal, o que é educomunicação? Núcleo de Comunicação e Educação da universidade de São Paulo. Disponível em:

<http://www.usp.br/nce/wcp/arq/textos/27.pdf >. Acessado em: 24 fev. 2014.

UNITED NATIONS REGIONAL INFORMATION CENTRE FOR WESTERN EUROPE (Site em português: Centro Regional de Informação das Nações Unidas). Alguns Factos e Números sobre as Pessoas com Deficiência. Síntese, 2013. Disponível em: <https://www.unric.org/pt/pessoas-com-deficiencia/5459> Acessado em: 19 fev. 2014.

UNIVERSIDADE DE SÃO PAULO. Declaração dos direitos do homem e do cidadão de 26 de agosto de 1789. Biblioteca virtual de direitos humanos, Universidade de São Paulo USP. Disponível em: <http://www.direitoshumanos.usp.br/index.php/Documentos-anteriores\%C3\%A0-cria\%C3\%A7\%C3\%A3o-da-Sociedade-das-Na\%C3\%A7\%C3\%B5es-at\%C3\%A91919/declaracao-de-direitos-do-homem-e-do-cidadao-1789.html>. Acesso em: 18 fev. 2014. 